\title{
Inhibition of 5-Lipoxygenase-activating Protein (FLAP) Reduces Pulmonary Vascular Reactivity and Pulmonary Hypertension in Hypoxic Rats
}

\author{
Norbert F. Voelkel, ${ }^{\star}$ Rubin M. Tuder, ${ }^{\ddagger}$ Kelly Wade, ${ }^{\ddagger}$ Marius Höper, ${ }^{\ddagger}$ Robert A. Lepley, ${ }^{\S}$ Jennifer L. Goulet," Beverly H. Koller," \\ and Frank Fitzpatrick ${ }^{\S}$ \\ *Pulmonary Hypertension Center, Departments of ${ }^{\ddagger}$ Pathology and ${ }^{\S}$ Pharmacology, University of Colorado Health Sciences Center, \\ Denver, Colorado 80262; and ${ }^{\|}$Department of Medicine, University of North Carolina, Chapel Hill, North Carolina 27599
}

\begin{abstract}
Chronically elevated shear stress and inflammation are important in hypertensive lung vessel remodeling. We postulate that 5-lipoxygenase (5-LO) is a molecular determinant of these processes. Immunohistology localized the 5-LO to macrophages of normal and chronically hypoxic rat lungs and also to vascular endothelial cells in chronically hypoxic lungs only. In situ hybridization of normal and chronically hypoxic lungs demonstrated that 5-LO mRNA is expressed in macrophages. Rats hypoxic for $4 \mathrm{wk}$-developed pulmonary hypertension increased translocation of the lung 5-LO from the cytosol to the membrane fraction and increased levels of lung tissue 5-lipoxygenase-activating protein (FLAP). A FLAP ligand, 3-[1-(4-chlorobenzyl)-3-t-butyl-thio-t-isopropylindol-2-yl]-2,2-dimethylpropanoic acid (MK-886), inhibited the acute angiotensin II and hypoxia-induced pulmonary vasoconstriction in vitro and the development of chronic hypoxic pulmonary hypertension in rats in vivo. Mice bred with the deletion of the 5-LO enzyme (5-LO knockout) developed less right heart hypertrophy than age-matched 5-LO competent mice. Our results support the hypothesis that the 5-LO is involved in lung vascular tone regulation and in the development of chronic pulmonary hypertension in hypoxic rodent models. (J. Clin. Invest. 1996. 97:2491-2498.) Key words: arachidonate 5-lipoxygenase - leukotriene - mice, knockout $\bullet$ hypertension, pulmonary $\bullet$ hypoxia
\end{abstract}

\section{Introduction}

Chronic pulmonary hypertension leads to remodeling of the lung vessels $(1,2)$. In human pulmonary hypertension and in animal models of experimental pulmonary hypertension, vasoconstriction causes vascular smooth muscle hypertrophy (1). In addition, high shear stress, inflammatory mediators, and growth factors participate in pulmonary endothelial cell damage and endothelial cell proliferation (1-4). Hypoxic vasocon-

Address correspondence to Norbert F. Voelkel, Pulmonary and Critical Care Division (C272), University of Colorado Health Sciences Center, 4200 E. Ninth Avenue, Denver, CO 80262. Phone: 303-2704211; FAX: 303-270-5632.

Received for publication 6 October 1995 and accepted in revised form 11 March 1996.

J. Clin. Invest.

(C) The American Society for Clinical Investigation, Inc.

0021-9738/96/06/2491/08 \$2.00

Volume 97, Number 11, June 1996, 2491-2498 striction is involved in the development of pulmonary hypertension, which accompanies many chronic lung diseases; whereas, nonhypoxic vasoconstriction due to unknown mediators may play a role in the rare form of unexplained, primary pulmonary hypertension $(5,6)$.

Our interest in the molecular mechanisms of pulmonary vascular remodeling is understandable when one considers the short survival time of patients with severe pulmonary hypertension (7). Although there are no animal models of primary pulmonary hypertension, the chronic pulmonary hypertension in animal models likely uses pathogenetic mechanisms relevant for the human disorder.

Chronic exposure of rats to hypoxia $(3,4)$ or a single injection of the alkaloid monocrotaline generates significant pulmonary hypertension (8). Our rationale for implicating 5-lipoxygenase $(5-\mathrm{LO})^{1}$ in pulmonary hypertension is based on the fact that agents that block the production of leukotrienes (LT) inhibit the development of pulmonary hypertension both in the hypoxia and the monocrotaline rat model (8-10). Confounding aspects of earlier studies were that the agents used to treat pulmonary hypertension were not specific, and little is known about the pathophysiological role of lung 5-LO. The consensus is that inflammatory cells, neutrophils, and macrophages are the source of 5-LO in the lung and that these cells can generate LT directly or via transcellular metabolism (11-15). Both chronic hypoxia and intravascular inflammation activate cytokine production in the lung $(4,16,17)$. The final signal transduction pathways leading to vascular remodeling in lung tissue may be similar or overlapping, whether triggered by increased shear stress, hypoxia, or inflammatory cells.

Here we investigate the role of 5-LO in pulmonary hypertension and report that 3-[1-(4-chlorobenzyl)-3-t-butyl-thio$t$-isopropylindol-2-yl]-2,2-dimethylpropanoic acid (MK-886) an inhibitor of the 5-LO:FLAP (5-lipoxygenase-activating protein) interactions $(18,19)$, decreases pulmonary vascular tone and inhibits the development of chronic hypoxic pulmonary hypertension. We have used antibodies (20) and a cDNA probe (21) to localize 5-LO and FLAP proteins and the 5-LO mRNA in the lung. The data indicate that the alveolar macrophages are the main source of lung 5-LO in normal and hypoxic rats; however, 5-LO also occurs in the endothelium of hypoxic rats. Further, we find evidence for activation of the 5-LO in chronically hypoxic lung tissue homogenates as demonstrated by the cytosol to membrane translocation of the en-

1. Abbreviations used in this paper: FLAP, 5-lipoxygenase-activating protein; 5-LO, 5-lipoxygenase; LT, leukotriene; MK-886, 3-[1-(4chlorobenzyl)-3-t-butyl-thio-t-isopropylindol-2-yl]-2,2-dimethylpropanoic acid. 
zyme. Lastly, 5-LO-deficient (22), chronically hypoxic mice developed less right heart hypertrophy than 5-LO-control mice.

\section{Methods}

Animals. 5-LO deficient mice (22) and male Sprague-Dawley rats (Harlan Sprague Dawley, Inc., Indianapolis, IN) were maintained at the University of Colorado Health Sciences Center Animal Resource Center. All animal experiments were conducted under protocols reviewed and approved by the University of Colorado Health Sciences Center Animal Care Committee.

Immune localization of 5-LO and FLAP in rat lungs. Frozen sections of rat lungs were immunostained as described (23). The anti5-LO polyclonal antibody LO32 (20) was used at a 1:50 dilution. Controls consisted of normoxic and hypoxic lungs incubated with a normal rabbit serum at the same dilution as used for the anti-5-LO antibodies. Specificity was further assessed by absorption of the LO32 antisera with 5-LO. Anti-5-LO antiserum was incubated with twofold excess of purified 5-LO $(35 \mu \mathrm{g}$ protein $/ 200 \mu \mathrm{l})$ for $3 \mathrm{~h}$ at $25^{\circ} \mathrm{C}$. After centrifugation at $12,000 \mathrm{~g}$, the supernatant was incubated with the frozen sections of rat lung. Unabsorbed antibody staining was performed in parallel slides. FLAP immunolocalization was performed in paraffin-embedded, formalin-fixed rat lungs. After paraffin removal in xylene, the sections were rehydrated and submitted to microwave treatment $(800 \mathrm{~W} / 10 \mathrm{~min})$ in $10 \mathrm{mM}$ citric acid monohydrate. After quenching of endogenous peroxidase with $3 \% \mathrm{H}_{2} \mathrm{O}_{2}$ for 25 min, the sections were exposed to anti-FLAP polyclonal antibody (20) (1:600 dilution) for $30 \mathrm{~min}$ and developed as described for the 5-LO immune staining.

In situ hybridization. mRNA in situ hybridization was performed as described (4). A 2.2-kb 5-LO insert spanning 34 bp of the $5^{\prime}$ untranslated region and $180 \mathrm{bp}$ of the $3^{\prime}$ untranslated sequence was excised with EcoRI and XbaI of p5LX and subcloned into EcoRI/XbaI digested pcDNA-III which was obtained from Invitrogen Corp. (San Diego, CA). Digoxigenin-labeled antisense and sense probes were synthesized from the T7 and SP-6 polymerase promoters, respectively (Genius IV kit; Boehringer Mannheim Biochemicals, Indianapolis, IN). The digoxigenin-labeled cRNA probes underwent alkaline hydrolysis for $25 \mathrm{~min}$ (4). The hybridization reaction progressed overnight at $42^{\circ} \mathrm{C}$ and was developed under dark conditions for $12 \mathrm{~h}$.

Immunochemical detection of 5-LO and FLAP in lung samples. Polyclonal rabbit antisera specific for 5-LO and for FLAP were provided by Dr. Jilly Evans (Merck-Frosst, Pointe Claire-Dorval, Canada). Goat anti-rabbit antiserum conjugated to horseradish peroxidase was obtained from Bio-Rad Laboratories (Richmond, CA), chemiluminescent reagents were from Amersham Corp. (Arlington Heights, IL), protein assay reagents were from Pierce (Rockford, IL) and fish skin gelatin was obtained from Norland Products (New Brunswick, $\mathrm{NJ})$. Frozen rat lung tissue $(0.50 \mathrm{~g})$ maintained at $-80^{\circ} \mathrm{C}$ was suspended in $0.05 \mathrm{M}$ phosphate, $\mathrm{pH} 7.1,0.1 \mathrm{M} \mathrm{NaCl}, 2 \mathrm{mM}$ EDTA, $0.5 \mathrm{mM}$ PMSF, $60 \mu \mathrm{g} / \mathrm{ml}$ soybean trypsin inhibitor $(2 \mathrm{ml})$, and homogenized for $3 \times 30$ s on ice (Tekmar Tissumizer, Cincinnati OH). Disrupted tissue was immediately sonicated $3 \times 20 \mathrm{~s}$ (power setting 3, 75\% duty cycle). Tissue debris were removed by centrifugation at $2,700 \mathrm{~g}$ for 20 $\min$ at $4^{\circ} \mathrm{C}$. After centrifugation, supernatant fractions designated total protein were prepared by mixing with $5 \times$ electrophoresis buffer (250 mM Tris- $\mathrm{HCl}, \mathrm{pH} 6.8,5 \% \mathrm{wt} / \mathrm{vol}$ SDS, $50 \%$ glycerol, $100 \mathrm{mg} / \mathrm{ml}$ DTT, and a trace of bromphenol blue), boiled for $5 \mathrm{~min}$, and held at $4^{\circ} \mathrm{C}$ while the protein content of each fraction was determined. The remaining supernatant fluid was centrifuged at 100,000 $g$ for $1 \mathrm{~h}$ at $4^{\circ} \mathrm{C}$ to generate a supernatant fraction (Cytosol) and pellet fraction (Membrane). A portion of the resulting cytosol and membrane fraction was immediately mixed with $5 \times$ electrophoresis buffer, boiled for $5 \mathrm{~min}$, and held on ice while the protein concentration of each fraction was quantified. To determine the relative 5-LO content of the various fractions, samples of total protein, cytosol, and membrane fractions containing equal amounts of protein were applied to $10 \%$ acrylamide gels with a $4 \%$ stacking gel and separated by electrophoresis. Samples of the membrane fractions containing equal quantities of protein were applied to $15 \%$ separating, $4 \%$ stacking gels to determine the relative FLAP content of the samples. After electrophoresis, proteins were transferred to nitrocellulose membranes. Membranes were saturated with $5 \%$ wt/vol nonfat dried milk to reduce nonspecific binding, then incubated with LO32 anti-5-LO antibody (20), 1:400 dilution, or H4 anti-FLAP antibody, 1:400 dilution, for $1.5 \mathrm{~h}$. The membrane was washed $4 \times 15 \mathrm{~min}$ in Tween-20 Trisbuffered saline (TBS) containing $0.1 \% \mathrm{vol} / \mathrm{vol}$ fish skin gelatin and incubated for $1 \mathrm{~h}$ with goat anti-rabbit antiserum conjugated with horseradish peroxidase (1:100,000 in Tween-20 TBS containing 1\% $\mathrm{vol} / \mathrm{vol}$ fish skin gelatin). Membranes were washed $4 \times 15 \mathrm{~min}$ in TBS Triton X-100, $0.1 \% \mathrm{vol} / \mathrm{vol}$, containing $0.1 \% \mathrm{vol} / \mathrm{vol}$ fish skin gelatin. Membranes were incubated with enhanced chemiluminescence reagents for $60 \mathrm{~s}$ and exposed with Kodak XAR-5 film. ATP purified 5-LO enzyme (24) was used as a standard on each gel. Film images obtained from Western blotting were processed on a Molecular Dynamics Computing Densitometer Model 300A scanning unit and the resulting densitometry data analyzed using Molecular ImageQuant 3.0 software (Molecular Dynamics Inc., Sunnyvale, CA).

Effect of MK-886 on lung perfusate thromboxane $B_{2}$ and $L T B_{4}$ levels. To assess the specificity of the FLAP inhibitor (18) on 5-LO product formation by the isolated lung, the rat lung perfused with Earle's balanced salt solution (EBSS) was used as described below, and the calcium ionophore A23187 $\left(10^{-5} \mathrm{M}\right)$ was added to the perfusate. Lung perfusion was stopped 10 min after addition of A23187 and the perfusate was assayed for the cyclooxygenase metabolite, thromboxane $\mathrm{B}_{2}$ and for the 5-LO metabolite, $\mathrm{LTB}_{4}$ by ELISA (25).

Effect of $M K-886$ on lung vascular reactivity. The isolated rat lung, perfused with a physiological salt solution, is a convenient preparation to assess the effects of naturally occurring mediators or drugs on lung vasomotor tone (26). Lungs were isolated from male SpragueDawley rats, perfused with EBSS at a constant perfusate flow of $0.3 \mathrm{ml} / \mathrm{kg}$ per min, and ventilated either with a gas mixture which contained $95 \%$ room air $+5 \% \mathrm{CO}_{2}$ or a gas mixture which contained no oxygen $\left(95 \% \mathrm{~N}_{2}\right.$ and $\left.5 \% \mathrm{CO}_{2}\right)$. After a preincubation and equilibration period of $30 \mathrm{~min}$, pulmonary vasoconstriction was elicited by injecting angiotensin II (A II) $(1 \mu \mathrm{g})$ into the pulmonary artery line or by switching the ventilation gas mixture from room air to $0 \%$ oxygen (hypoxic pressor response). After two pairs of A II and hypoxiainduced pressor responses, the FLAP ligand, MK-886 (Dr. Jilly Evans, Merck-Frosst, Pointe Claire-Dorval, Canada) was added to the perfusate reservoir; and $10 \mathrm{~min}$ after MK-886 addition, the pressor responses to A II, alveolar hypoxia, or phorbol 12-myristate acetate (PMA) $\left(10^{-8} \mathrm{M}\right)$ were examined. The data were compared with timematched controls perfused with DMSO only.

Effect of chronic MK-886 treatment on the development of hypoxia-induced pulmonary hypertension. The degree of pulmonary hypertension due to hypobaric hypoxia after chronic $(28 \mathrm{~d})$ exposure in a high altitude chamber was assessed in two groups of rats: rats treated with MK-886 $30 \mathrm{mg} / \mathrm{kg}$ (dissolved in $50 \mu \mathrm{l}$ DMSO) or rats treated with $50 \mu \mathrm{l}$ DMSO vehicle via single daily i.p. injection. Rats were exposed to a simulated altitude of $16,000 \mathrm{ft}$. for $28 \mathrm{~d}$, then removed from the chamber for measurement of the pulmonary artery pressure $(3,4)$. Subsequently, the animals were killed, and the hematocrit and the ratio of right ventricle wt/left ventricle and septum wt as an index of right heart hypertrophy were measured.

Development of right ventricular hypertrophy in chronically hypoxic 5-LO knockout mice. 5-LO-deficient (22) and normal control congenic mice were exposed to hypobaric hypoxia as described above. At the end of the exposure time, the animals were removed from the high altitude chamber, killed, and the hematocrit and the ratio of right ventricular wt/left ventricle plus septum wt were measured. Lungs were fixed in buffered formalin for routine lung histology.

Statistics. Data are displayed as the mean \pm SEM. The significance of differences observed between experimental treatment groups was calculated using paired Student's $t$ test. 

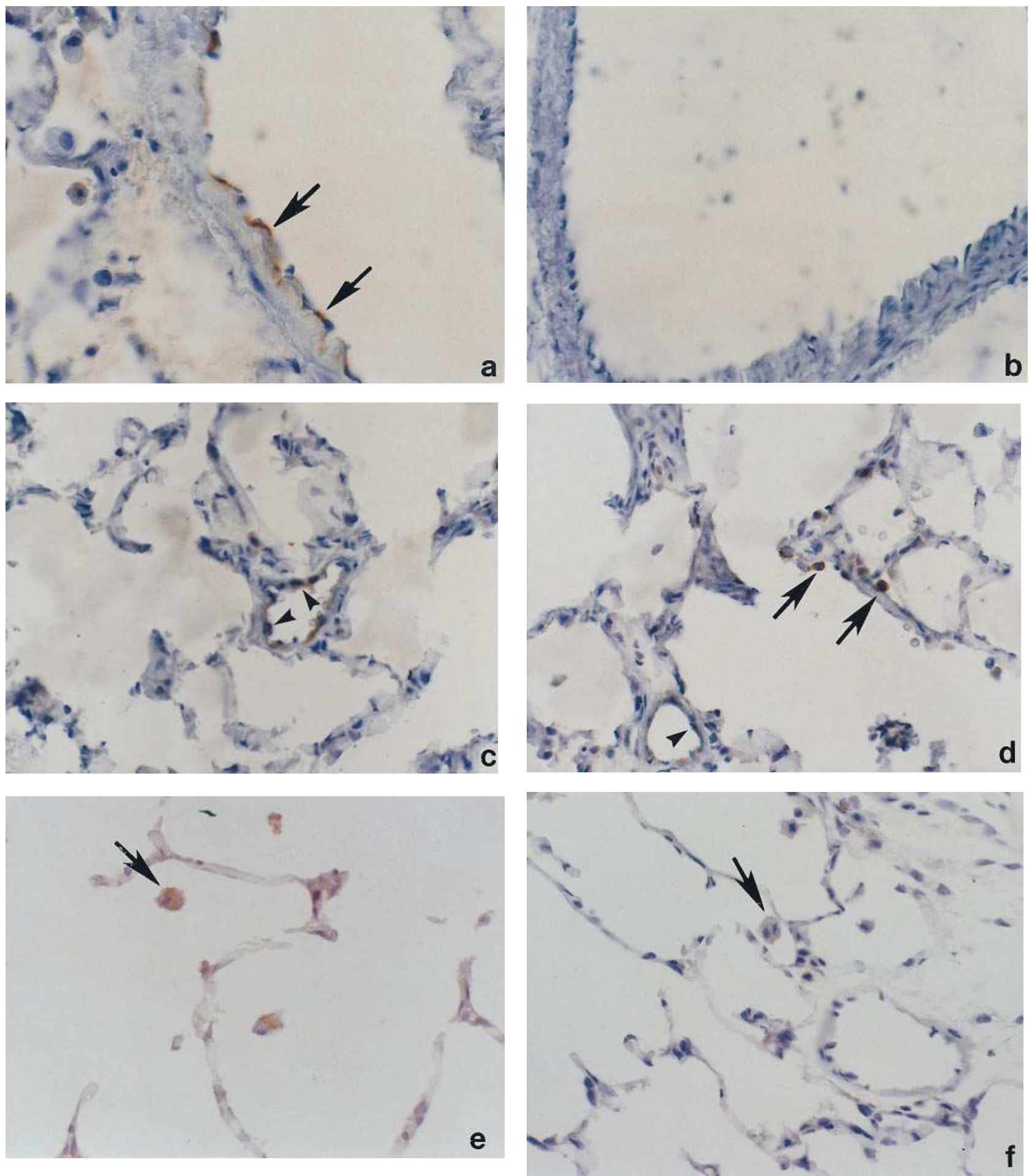

Figure 1. Immunohistochemical localization of 5-LO in rat lungs. Endothelial cells lining a large pulmonary artery in a 4-wk hypoxic rat lung express 5-LO (a, arrows, immunoperoxidase $\times 400)$, whereas no 5-LO immunoreactivity is present in the normoxic rat lung $(b$, immunoperoxidase, $\times 400)$. Small pulmonary arteries in 4-wk hypoxic rat lungs exhibit 5-LO immunoreactivity localized to endothelial cells (c, arrowheads) but not to alveolar septa or vascular smooth muscle cells. In addition, alveolar macrophages also exhibit 5-LO $(d$, arrows $)(c$ and $d$, immunoperoxidase, $\times 200$ ). Immunoreactivity of 5-LO present predominantly in alveolar macrophages in 4-wk hypoxic rat lungs (e, arrows) is completely abrogated by preincubation of LO32 antiserum with purified 5-LO $(f$, arrows, $\times 400)$.

\section{Results}

Immune localization of 5-LO and FLAP in rat lungs. The anti5-LO antibody (LO32) stained alveolar macrophages in lungs from normoxic rats. The anti-5-LO antibody (LO32) stained alveolar macrophages and also small artery endothelial cells (Fig. 1) in lungs from animals exposed to hypoxia for 4 wk. The endothelial cell 5-LO staining did not occur with the lung sections from hypoxic rats when anti-5-LO was preabsorbed 

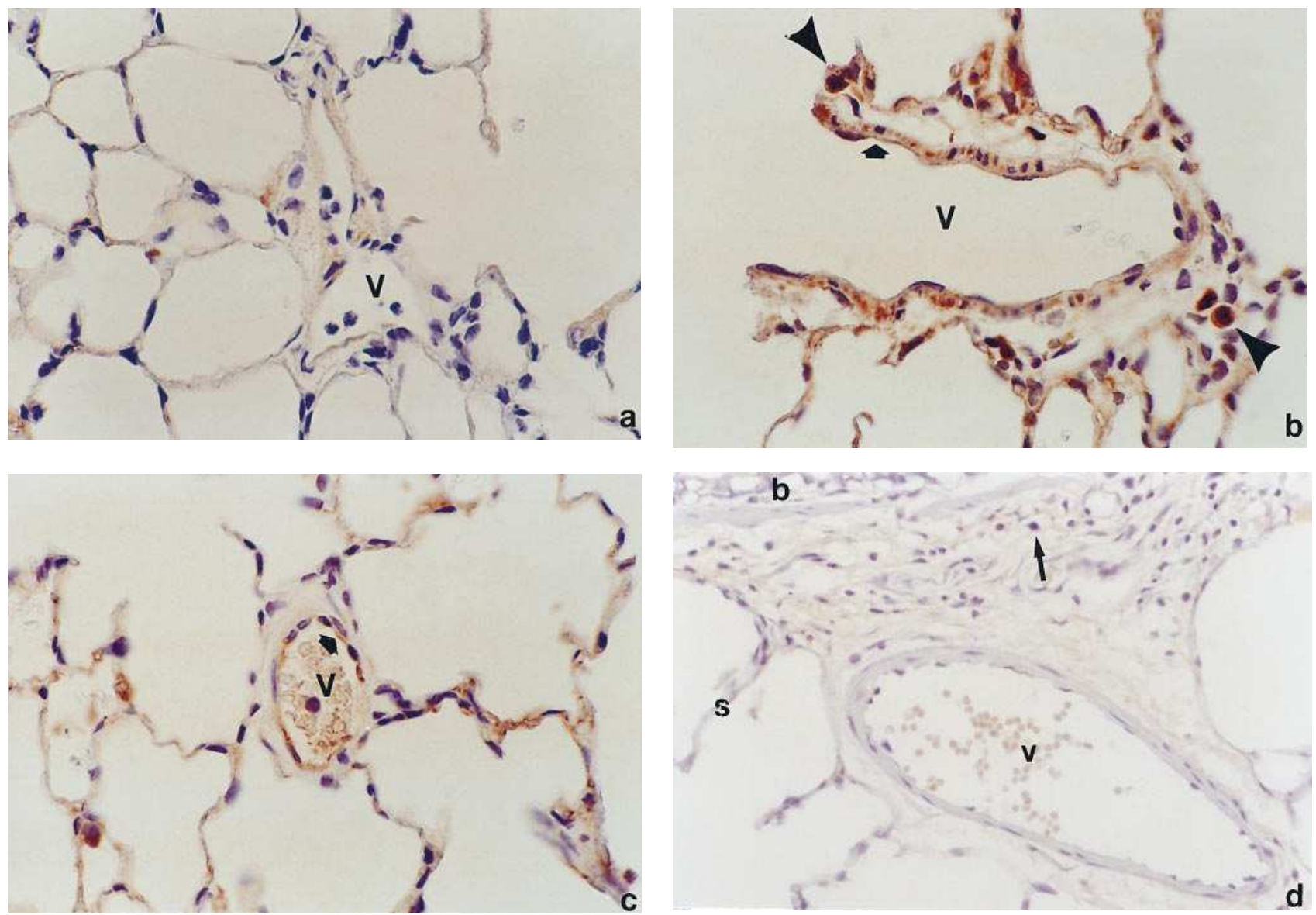

Figure 2. Immunohistochemical localization of FLAP in rat lungs. (a) Normoxic lung does not express detectable FLAP in endothelial cells in pulmonary vessels $(V)$, or in circulating inflammatory cells. $(b)$ Mononuclear cells (arrowheads) located in the perivascular region of 4-wk hypoxic rat lung express FLAP. Endothelial cells (arrow) in pulmonary vessels $(V)$ also express reactivity with FLAP antibody. (c) 4-wk hypoxic lung with strong reactivity for FLAP in endothelial cells (arrows). Note focal expression of FLAP in alveolar septa ( $a, b, c$, Immunoperoxidase, $\times 400)$. Normal rabbit serum control $(d)$ in a 4-wk hypoxic lung. In contrast to the 5-LO (Fig. $1 b)$ and FLAP (Fig. $2 c$ ) immunostaining observed in the hypoxic 4-wk lung, no immunoreactivity is evident in the pulmonary artery $(V)$, alveolar septa $(S)$, perivascular inflammatory cells $($ arrow) or bronchiolar lining cells $(b$, Immunoperoxidase, $\times 200)$.

with purified 5-LO protein. FLAP expression was increased in the 4-wk hypoxic rat lung when compared with normoxic controls. FLAP was predominantly localized in the endothelial cells of small- and medium-sized pulmonary arterioles and in alveolar and interstitial macrophages. Focal FLAP immunostaining was also present in alveolar septa, probably within inflammatory cells migrating through the lung (Fig. 2).

In situ hybridization. Sections from control rat lungs and from the lungs of rats which were exposed to hypobaric hypoxia for 3, 7, and $28 \mathrm{~d}$ were examined. The specific antisense probe revealed 5-LO-mRNA labeling of alveolar macrophages. There appeared to be no significant difference in the frequency or intensity of the signal of labeled cells between control and hypoxic lungs. Notably, there was no specific labeling of endothelial cells in any of the lung sections (Fig. 3). These results were confirmed in three independent experiments.

Western analysis of 5-LO and FLAP in rat lung. Immunoblotting confirmed the presence of 5-LO in lungs from normoxic and hypoxic rats. Fig. 4 a (top) depicts 5-LO in total protein samples prepared from rat lung tissue. Comparison of normoxic control rats (lane 1) with hypoxic rats (lane 2) indicates that total 5-LO content of lung tissue was diminished after $4 \mathrm{wk}$ of hypobaric hypoxia. Analysis by densitometry established that control 5-LO (lane 1) was 2.0-fold greater than that seen in hypoxic lung tissue (lane 2). To determine the intracellular distribution of 5-LO in lung tissue, cytosol and membrane fractions were prepared and analyzed by immunoblotting (Fig. $4 a$, bottom). 5-LO in both control (lane 1) and hypoxic (lane 2) lung samples appeared predominantly in the $100,000 \mathrm{~g}$ membrane fraction. This conclusion was substantiated by densitometry. In the control, membrane fraction 5-LO was 6.1-fold greater than the cytosolic fraction (lane 1). Similarly, after 4 wk of hypobaric hypoxia (lane 2), 5-LO in the membrane fraction was 8.6-fold greater than the corresponding cytosolic fraction. Comparison of the upper panel total protein samples and the 5-LO distribution samples shows a consistent pattern of diminished 5-LO in hypoxic rat lung. These differences are 2.0-fold in total protein, 2.6-fold in cytosol, and 1.9-fold in membrane samples. In contrast, FLAP was increased 2.7-fold over control values in lung tissue after 4 wk of hypobaric hypoxia (Fig. 4b). A 1.4-fold increase in FLAP protein was observed in hypoxic lung fractions after daily injection of MK-886 (Fig. $4 b$ ).

Effect of MK-886 on production of $\mathrm{LTB}_{4}$ and thromboxane $B_{2}$ and pulmonary vasoconstriction in vitro. Addition of MK- 

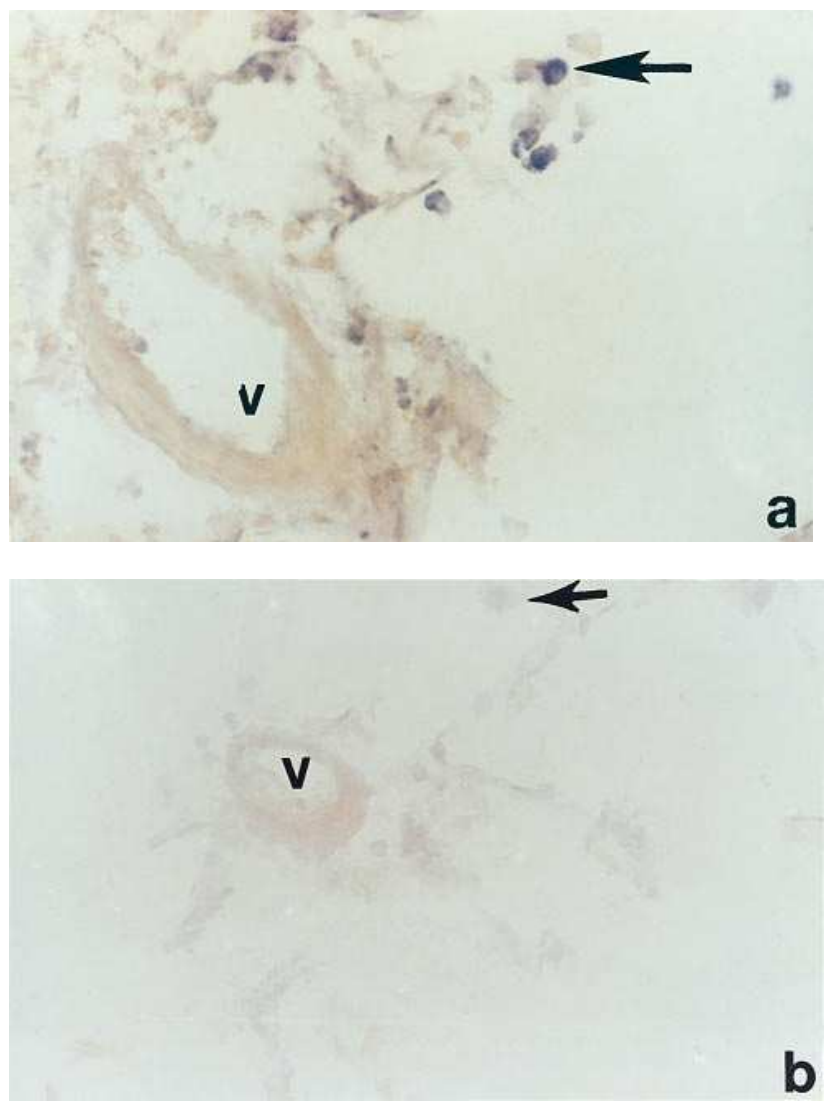

Figure 3. In situ hybridization for 5-LO mRNA in hypoxic rat lungs. (a) Note intense hybridization signal for 5-LO transcripts in alveolar macrophages (arrows) but not in endothelial cells of a small pulmonary artery $(v)$. (b) The hybridization signal is absent in parallel sections hybridized with the sense control probe. $(\times 400)$.

$886\left(10^{-5} \mathrm{M}\right)$ to the perfusate of the isolated lungs $10 \mathrm{~min}$ before challenge with A23187 $\left(10^{-5} \mathrm{M}\right)$ reduced the perfusate content of $\mathrm{LTB}_{4}$ but had no effect on thromboxane $\mathrm{B}_{2}$ (data not shown). Because MK-886 at $10^{-5} \mathrm{M}$ selectively inhibited A23187-triggered LT production, this concentration was used to modulate the vasoconstrictor response to angiotensin II, alveolar hypoxia, and PMA, in vitro. Perfusate concentrations lower than $10^{-5} \mathrm{M} \mathrm{MK}-886$ did not affect pulmonary vasoconstriction; however, $10^{-5} \mathrm{M} \mathrm{MK}-886$ significantly reduced the angiotensin II-induced pressor response $(4.5 \pm 1 \mathrm{mmHg}$ vs. $11 \pm 1 \mathrm{mmHg}, P<0.05)$ and the hypoxic pressor response $(1.5 \pm 1 \mathrm{mmHg}$ vs. $11 \pm 1 \mathrm{mmHg}, P<0.05)$. The more gradually developing vasoconstriction which occurred after addition of PMA $\left(10^{-8} \mathrm{M}\right)$ to the perfusate was unaltered by MK-886 $\left(10^{-5} \mathrm{M}\right)(18 \pm 2 \mathrm{mmHg}$ vs. $20 \pm 2 \mathrm{mmHg})$ indicating that it had not acted as a vasodilator.

Effect of chronic MK-886 on chronic pulmonary hypertension. When rats received daily injections of MK-886 $(30 \mathrm{mg} / \mathrm{kg}$, i.p.), the degree of pulmonary hypertension and right ventricular hypertrophy was less at the end of the 4 wk of chronic hypobaric hypoxia compared to rats treated identically with DMSO vehicle (Fig. 5, $A$ and $B$ ).

Right ventricular hypertrophy in 5-LO knockout mice. Chronic hypobaric hypoxia resulted in a reduced right ventricle wt/left ventricle plus septum $(\mathrm{RV} / \mathrm{LV}+\mathrm{S})$ wt ratio in the 5-LO
$78 \mathrm{kD}$

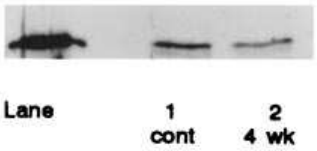

5LO Distribution
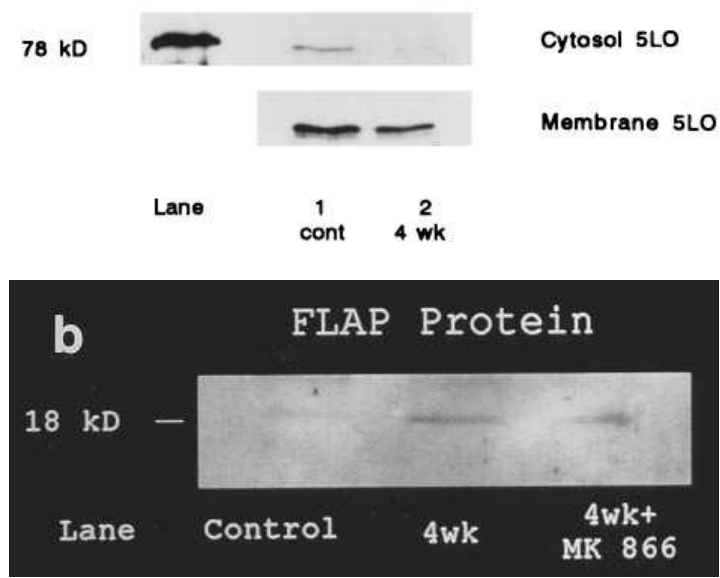

Figure 4. (a) Western analysis of 5-LO obtained from rat lung tissue. Equal quantities of protein, $10 \mu \mathrm{g} / \mathrm{lane}$, prepared from frozen rat lung tissue were separated on $10 \%$ acrylamide gels under reducing conditions. Top, comparison of total 5-LO enzyme in rat lung tissue. Lane 1, control rat lung tissue. Lane 2, 4-wk hypoxic rat lung tissue. A 78-kD 5-LO standard is shown to the left of the treatment groups. Bottom, comparison of 5-LO distribution in rat lung tissue cytosol and membrane fractions. The amount of membrane-associated enzyme is depicted directly below the amount of cytosolic enzyme. Lane 1, control rat lung tissue. Lane 2, 4-wk hypoxic rat lung tissue. A 78-kD 5-LO standard is shown to the left of the treatment groups. (b) Western analysis of FLAP obtained from rat lung tissue. Equal quantities of protein, $10 \mu \mathrm{g} / \mathrm{lane}$, prepared from frozen rat lung tissue were separated of a $15 \%$ acrylamide gel under reducing conditions. Lane 1, control rat lung tissue. Lane 2, 4-wk hypoxic rat lung tissue. Lane 3, MK-886-treated 4-wk hypoxic rat lung tissue.

knockout mice $(0.32 \pm 0.01)$ when compared to the 5-LO competent control mice $(0.47 \pm 0.03, P<0.05)$ (Fig. 6).

\section{Discussion}

The cellular sites of 5-LO gene expression and the intracellular distribution of the 5-LO were investigated in lung tissues obtained from normal and chronically hypoxic, pulmonary hypertensive rats. In situ hybridization shows that macrophages are the major cell source for 5-LO in the rat lung, and our immunohistology studies support this conclusion. Immunochemical data show that chronic hypoxia and pulmonary hypertension provide conditions favoring cytosol to membrane translocation of the 5-LO and conditions for detection of 5-LO in lung endothelial cells. In addition, chronic hypoxia and/or chronic pulmonary hypertension leads to an increase in FLAP protein in 

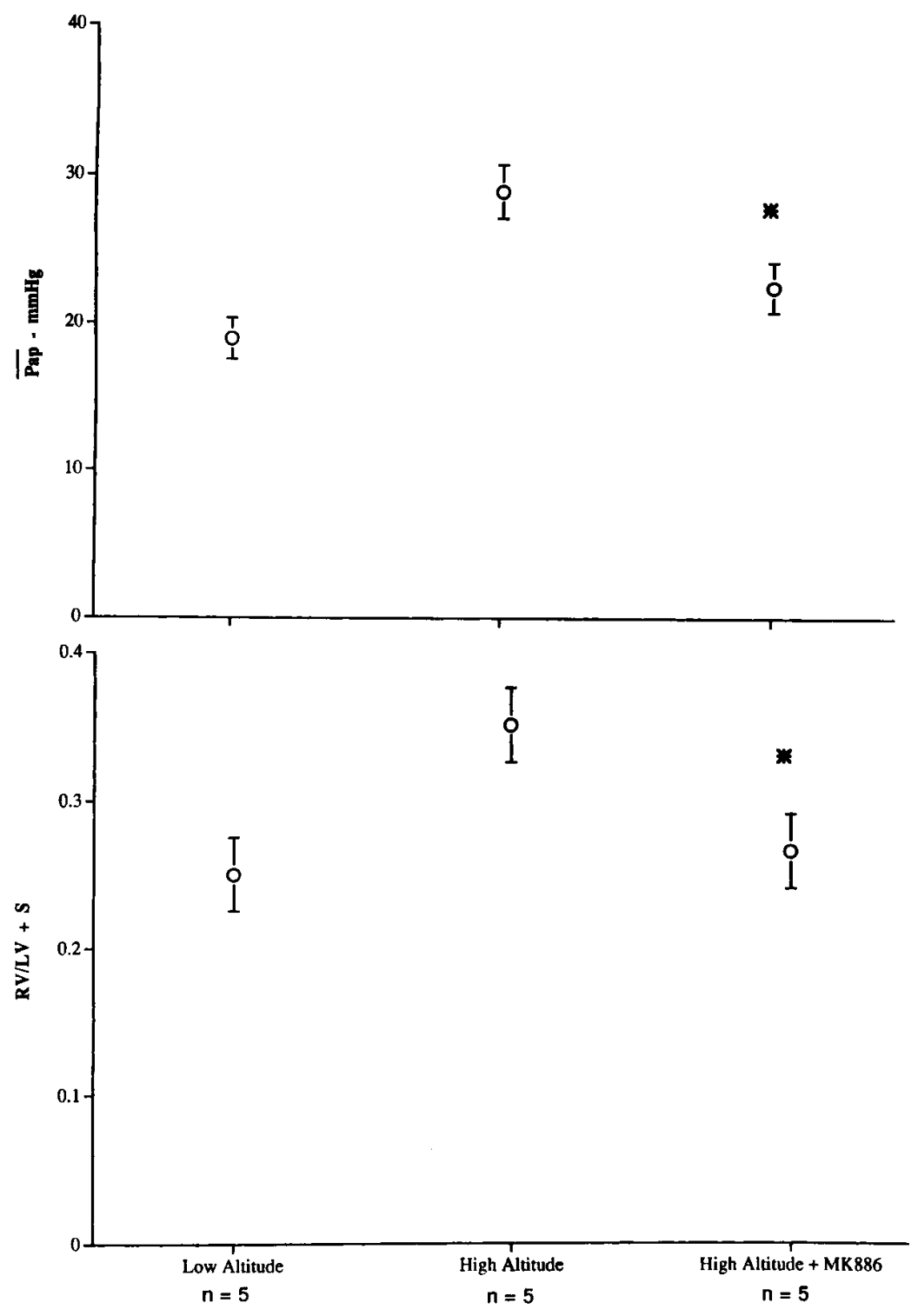

Figure 5. Daily i.p. injection of MK-886 decreases the mean pulmonary artery pressure $(P p a)(A)$ and the degree of right heart hypertrophy [wt of the right ventricle/wt of left ventricle plus septum] $(B)$ after 4-wk of hypobaric hypoxia (simulated altitude of $16,000 \mathrm{ft}$ ) when compared to hypoxic rats treated with solvent (DMSO). the lungs. Assessment of the role of 5-LO in the lung based on treatment of isolated perfused lungs or of chronically hypoxic rats with MK-886, an antagonist of FLAP:5-LO interactions, supports the conclusion that the 5-LO activity contributes to lung vascular tone regulation and plays a role in the development of pulmonary hypertension. The observation that 5-LOdeficient (5-LO knockout) mice (22) exposed to hypoxia develop less right heart hypertrophy than congenic control mice which possess a functional 5-LO gene is also consistent with this conclusion.

In normoxic and hypoxic animals 5-LO occurs prominently in macrophages; however, in the chronically hypoxic, hypertensive lungs, the anti-5-LO antibody also labeled small vessel endothelial cells (Fig. 1). We emphasize that this staining did not occur in lungs from normoxic control rats, and preabsorption of the antibody with purified 5-LO protein abolished both
CONTROL

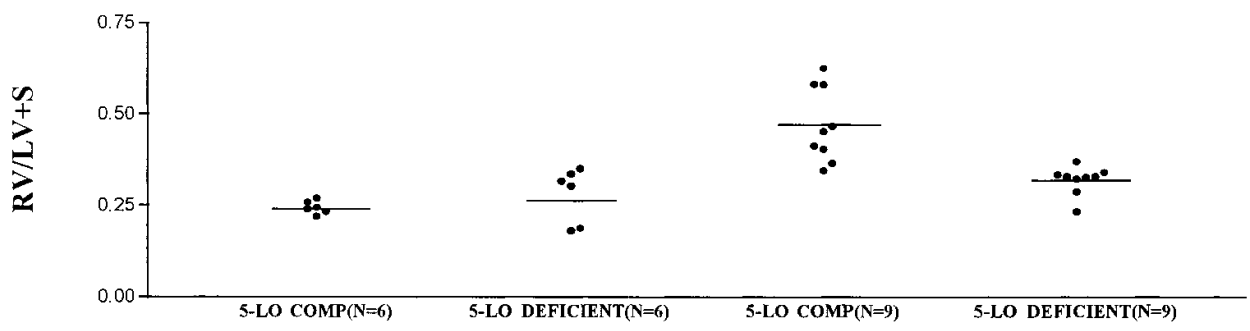

Figure 6. Effect of exposure of 5-LO competent (5-LO comp) and 5-LOdeficient mice to $3 \mathrm{wk}$ of hypobaric hypoxia. Control animals were housed at 5,280 ft (Denver, CO). Shown are individual animal data for the ratio of the right ventricular wt/left ventricle plus septum wt $(\mathrm{RV} / \mathrm{LV}+\mathrm{S})$. 
macrophage and endothelial cell labeling in control or chronically hypoxic lungs. One plausible explanation for this novel observation is that LO32 detects a 5-LO isozyme. Although the current consensus is that isolated endothelial cells are unable to produce LT (13) via 5-LO activation, Claesson et al. (12) observed that human umbilical cord vein-derived endothelial cells produced both $\mathrm{LTC}_{4}$ and $\mathrm{LTB}_{4}$ after addition of $\mathrm{LTA}_{4}$, provided that the cells had been cultured for 10-16 d; freshly isolated cells did not metabolize $\mathrm{LTA}_{4}$. This implies that a phenotype switch may occur during culture. By analogy, hypoxia affects gene expression in cultured endothelial cells $(16,17)$ and in isolated perfused lungs (27). Thus, we speculate that during chronic hypoxia and/or under the influence of increased shear stress and cytokine release some lung vascular endothelial cells acquired a phenotype which can express a form of 5-LO or a protein with an epitope recognized by antibody LO32. Of interest is a report which demonstrates that HL-60 cells and brain tumors contain several 5-LO transcripts (28). Our in situ gene expression studies demonstrate that the 5-LO mRNA is not expressed abundantly in lung cells. This conforms with the report of Kaneko et al. (11) showing that lung tissue contained approximately one-tenth of the neutrophil 5-LO activity.

Chronic hypoxia did not increase lung 5-LO protein, according to our in situ hybridization and Western blot data. However, 4 wk of chronic hypoxia caused a detectable shift of 5-LO from the cytosol to the membrane fraction of lung homogenate (Fig. $4 a$ ). If most of the lung tissue 5-LO is localized to macrophages, then this 5-LO translocation may have originated from or contributed to the hypertensive phenotype. In resting alveolar macrophages, 5-LO is mainly associated with the membrane fraction (29). Our data with normoxic lungs are consistent with the earlier finding by Coffey et al. (29). The translocation of the residual, cytosolic 5-LO to the membranes may constitute part of the mechanism of lung 5-LO activation in chronic hypoxia/pulmonary hypertension. Alternatively, chronic hypoxia may enhance interactions between 5-LO and the membrane via the stoichiometric excess of FLAP or via other macromolecules. Increased intracellular calcium induced by chronic hypoxia (30) may also have contributed to 5-LO translocation in the lung cells. This is also likely the cause of hypoxia- and angiotensin II-induced pulmonary vasoconstriction (31).

In contrast to the 5-LO protein, which did not increase during chronic hypoxia/pulmonary hypertension, FLAP was more abundant in lungs from chronically hypoxic rats. Thus, in rat lungs, under the conditions of hypoxia-induced pulmonary hypertension, the role of the 5-LO system may involve both its translocation and increased FLAP availability. MK-886, an antagonist of FLAP:5-LO binding, affected both the magnitude of acute hypoxic vasoconstriction and the development of chronic pulmonary hypertension. Both pulmonary artery pressure and right heart hypertrophy were decreased in rats chronically treated with daily injections of MK-886. Two structurally distinct inhibitors of LT formation, diethylcarbamazine (9) and CGS22745 (10), had previously been shown to inhibit the development of chronic hypoxic pulmonary hypertension in rats. Whether MK-886 inhibited the development of chronic pulmonary hypertension because of direct inhibition of hypoxia-induced pulmonary vasoconstriction or because of inhibition of vascular remodeling was not investigated in the present study.

In summary, rats that demonstrate pulmonary hyperten- sion and vascular remodelling after chronic exposure to high altitude provide evidence for: $(a)$ a redistribution of cellular 5-LO protein from the soluble cytosolic fraction to the membrane particulate fraction, $(b)$ an increase in immunologically detectable FLAP protein, and $(c)$ the appearance of 5-LO protein in vascular endothelial cells. The redistribution of cellular 5-LO in the presence of increased FLAP protein may represent augmented vascular cell activity in hypertensive lung tissue. Although the effect that 5-LO inhibitors have on the development of chronic hypertension has not been extensively studied and reported on, studies that have examined the effect of various 5-LO inhibitors and leukotriene antagonists have produced inconsistent results (for review see references 32, 33). These conflicting reports suggest that the participation of 5-LO in the development of this condition may involve both an enzymatic component associated with leukotriene production and a nonenzymatic component determined by interactions between 5-LO and other macromolecules involved in cellular activation. The data presented in this work and a recent communication (34) provide the first evidence that demonstrates that a 5-LO FLAP-binding antagonist, MK-886, alters vasoconstriction in perfused rat lungs. The strength of this evidence rests upon the use of a well established preparation for the study of pulmonary vascular tone and the selectivity of MK-886 as used in this preparation. Although models which describe inhibition of the monovalent current carried by a potassium channel have been advanced to provide a mechanistic basis for hypoxic pulmonary vasoconstriction $(35,36,37)$, evidence linking MK-886 to cellular ion gated channel activity is lacking at present. In conclusion, the data presented indicate that 5-LO participates in modulating lung vascular tone and possibly in the remodelling of lung vasculature.

\section{Acknowledgments}

The technical assistance of Jenny Allard and the secretarial support of Nancy Hart and Velma Parker are gratefully acknowledged.

This work has been supported by a grant from the University of Colorado Health Sciences Center to the Pulmonary Hypertension Center and by a Grant-in-Aid from the American Heart Association (to N.F. Voelkel) and ROI AI 26730 (to F.A. Fitzpatrick).

\section{References}

1. Reeves, J.T., and N.F. Voelkel. 1989. Mechanisms of chronic pulmonary hypertension: Basic considerations. In Pulmonary Circulation. C.A. Wagenvoort and H. Denolin, editors. Elsevier Science Publishing Co., New York. 27-39.

2. Tuder, R.M., B. Groves, D.B. Badesch, and N.F. Voelkel. 1994. Exuberant endothelial cell growth and elements of inflammation are present in plexiform lesions of pulmonary hypertension. Am. J. Pathol. 144:275-285.

3. Ono, S., J.Y. Westcott, and N.F. Voelkel. 1992. PAF antagonists inhibit pulmonary vascular remodeling induced by hypobaric hypoxia in rats. J. Appl. Physiol. 73:1084-1092.

4. Voelkel, N.F., R.M. Tuder, J. Bridges, and W.P. Arend. 1994. Interleukin-1 receptor antagonist treatment reduces pulmonary hypertension generated in rats by monocrotaline. Am. J. Respir. Cell Mol. Biol. 11:664-675.

5. Voelkel, N.F. 1993. Pulmonary hypertension: from phenomenology to a molecular understanding of disease mechanisms. In Ion Flux in Pulmonary Vascular Control. E. K. Weir, editor. Plenum Press, New York. 1-14.

6. Wagenvoort, C.A., and N. Wagenvoort. 1977. Pathology of Pulmonary Hypertension. Elsevier Science Publishing Co., New York. 345 pp.

7. D'Alonzo, G.E., R.J. Barst, S.M. Ayers, E.H. Bergofsky, B.H. Brundage, K.M. Detre, A.P. Fishman, R.M. Goldring, B.M. Groves, J.T. Kernis, et al. 1991. Survival in patients with primary pulmonary hypertension. Ann. Intern. Med. 115:343-349.

8. Stenmark, K.R., M.L. Morganroth, N.F. Voelkel, R.C. Murphy, P.M. Henson, M.M. Mathias, and J.T. Reeves. 1985. Alveolar inflammation and arachidonate metabolism in monocrotaline-induced pulmonary hypertension. 
Am. J. Physiol. 248:H859-H866.

9. Morganroth, M.L., K.R. Stenmark, K.G. Morris, R.C. Murphy, M. Mathias, J.T. Reeves, and N.F. Voelkel. 1985. Diethylcarbamazine inhibits acute and chronic hypoxic pulmonary hypertension in awake rats. Am. Rev. Respir. Dis. 131:488-492.

10. Voelkel, N.F., T.J. McDonnell, S.W. Chang, M. Bugnitz, J.Y. Westcott, and K.R. Stenmark. 1987. The future for drugs affecting the lipoxygenase pathway in the treatment of pulmonary hypertension and ARDS. IBC Tech. Serv. 1-11.

11. Kaneko, S., N. Ueda, T. Tonai, T. Maruyama, T. Yoshimoto, and S. Uamamoto. 1987. Arachidonate 5-lipoxygenase of porcine leukocytes studied by enzyme immunoassay using monoclonal antibodies. J. Biol. Chem. 262:67416745.

12. Claesson, H.E., H. Haeggström, B. Odlander, J.F. Medina, A. Wetterholm, P. Jakobsson, and O. Radmark. 1991. The role of leukotriene $\mathrm{A}_{4}$ hydrolase in cells and tissues lacking 5-lipoxygenase. In Cell-cell Interactions in the Release of Inflammatory Mediators. P.Y.-K. Wong and C. N. Serhan, editors. Plenum Press, New York. 307-315.

13. Feinmark, S.J., and P.J. Cannon. 1986. Endothelial cell leukotriene $\mathrm{C}_{4}$ synthesis results from intercellular transfer of leukotriene $\mathrm{A}_{4}$ synthesized by polymorphonuclear leukocytes. J. Biol. Chem. 261:16466-16472.

14. Nishida, M., T. Kuzuya, S. Hoshida, Y. Kim, A. Kitabatake, T. Kamada, and M. Tada. 1990. Polymorphonuclear leukocytes induced vasoconstriction in isolated canine coronary arteries. Circ. Res. 66:253-258.

15. Sala, A., G. Rossoni, F. Buccellati, F. Berti, G. Folco, and J. Maclouf. 1993. Formation of sulphidopeptide-leukotrienes by cell-cell interaction causes coronary vasoconstriction in isolated, cell-perfused heart of rabbit. Br. J. Pharmacol. 110:1206-1212.

16. Karakurum, M., R. Shreeniwas, J. Chen, D. Pinsky, S.-D. Yan, M. Anderson, K. Sunouchi, J. Major, K. Kuwabara, A. Rot, R. Nowygrod, and D. Stern. 1994. Hypoxic induction of interleukin-8 gene expression in human endothelial cells. J. Clin. Invest. 93:1564-1570.

17. Shreeniwas, R., S. Koga, M. Karakurum, K. Pinsky, E. Kaiser, J. Brett, B.A. Wolitzky, C. Norton, J. Plocinski, W. Benjamin, D.K. Burns, A. Goldstein, and D. Stern. 1992. Hypoxia-mediated induction of endothelial cell interleukin-

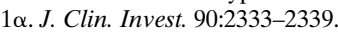

18. Ford-Hutchinson, A.W. 1990. Modification of the lipoxygenase pathway of arachidonic acid metabolism. In Advances in Prostaglandin, Thromboxane and Leukotriene Research. B. Samuelsson, S.-E. Dahlén, J. Fritsch, and P. Hedqvist, editors. Raven Press Ltd., New York. 161-169.

19. Ford-Hutchinson, A.W., M. Gresser, and R.N. Young. 1994. 5-lipoxygenase. Annu. Rev. Biochem. 63:383-417.

20. Kargman, S., P.J. Vickers, and J.F. Evans. 1992. A23187-induced translocation of 5-lipoxygenase in osteosarcoma cells. J. Cell Biol. 119:1701-1709.

21. Funk, C.D., H. Gunne, H. Steiner, T. Izumi, and B. Samuelsson. 1989. Native and mutant 5-lipoxygenase expression in a baculovirus/insect cell system. Proc. Natl. Acad. Sci. USA. 86:2592-2596.

22. Goulet, J.L., J.N. Snouwaert, A.M. Latour, T.M. Coffman, and B.H. Koller. 1994. Altered inflammatory responses in leukotriene-deficient mice.
Proc. Natl. Acad. Sci. USA. 91:12852-12856.

23. Halbower, A.C., R.J. Mason, S.H. Abman, and R.M. Tuder. 1994. Agarose infiltration improves morphology of cryostat sections of lung. Lab. Invest. 71:149-153.

24. Lepley, R.A., and F.A. Fitzpatrick. 1994. 5-lipoxygenase contains a functional Src homology 3-binding motif that interacts with the Src homology 3 domain of Grb2 and cytoskeletal proteins. J. Biol. Chem. 269:24163-24168.

25. Westcott, J.Y., S. Chang, M. Balazy, D.O. Stene, P. Pradelles, J. Maclouf, N.F. Voelkel, and R.C. Murphy. 1986. Analysis of 6-keto PGF P $_{1 \alpha}, 5$-HETE, and $\mathrm{LTC}_{4}$ in rat lung: comparison of GM/MS, RIA, and EIA. Prostaglandins. 32: $857-873$.

26. Chang, S.-W., and N.F. Voelkel. 1991. The isolated perfused lung preparation as a research tool. In Comparative Biology of the Normal Lung. R.A. Parent, editor. CRC Press, Boca Raton, FL. 587-613.

27. Tuder, R.M., B.E. Flook, and N.F. Voelkel. 1995. Increased gene expression for VEGF and the VEGF receptors $K D R / F l k$ and Flt in lungs exposed to acute or to chronic hypoxia. Modulation of gene expression by nitric oxide. J. Clin. Invest. 95:1798-1807.

28. Boado, R.J., W.M. Pardridge, H.V. Vinters, and K.L. Black. 1992. Differential expression of arachidonate 5-lipoxygenase transcripts in human brain tumors: evidence for the expression of a multitranscript family. Proc. Natl. Acad. Sci. USA. 89:9044-9048.

29. Coffey, M., M. Peters-Golden, J.C. Fantone, III, and P.H.S. Sporn. 1992. Membrane association of active 5-lipoxygenase in resting cells. J. Biol. Chem. 267:570-576.

30. Cornfield, D.N., T. Stevens, I.F. McMurtry, S.H. Abman, and D.M. Rodman. 1993. Acute hypoxia increases cytosolic calcium in fetal pulmonary artery smooth muscle cells. Am. J. Physiol. 265:L53-L56.

31. McMurtry, I.F., A.B. Davidson, J.T. Reeves, and R.F. Grover. 1976. Inhibition of hypoxic pulmonary vasoconstriction by calcium agonists in isolated rat lungs. Circ. Res. 38:99-104.

32. Voelkel, N.F., S.W. Chang, T.J. McDonnell, and J. Haynes. 1987. Role of membrane lipids in the control of normal vascular tone. Am. Rev. Respir. Dis. 136:214-217.

33. McDonnell, T.J., J.Y. Westcott, J. Czartolomna, and N.F. Voelkel. 1990 Role of peptidoleukotrienes in hypoxic pulmonary vasoconstriction in rats. Am. J. Physiol. 259:H751-H758.

34. Voelkel, N.F., K. Lobel, J.Y. Westcott, and T.J. Burke. 1995. Nitric oxiderelated vasoconstriction in lungs perfused with red cell lysate. FASEB J. 9:379-386.

35. Post, J.M., J.R. Hume, S.L. Archer, and E.K. Weir. 1992. Direct role for potassium channel inhibition in hypoxic pulmonary vasoconstriction. Am. J. Physiol. 262:C882-C890.

36. Yuan, X.-J., W.F. Goldman, M.L. Tod, L.J. Rubin, and M.P. Blaustein. 1993. Hypoxia reduces potassium currents in cultured rat pulmonary but not mesenteric arterial myocytes. Am. J. Physiol. 264:L116-L123.

37. Weir, E.K., and S.L. Archer. 1995. The mechanism of acute hypoxic pulmonary vasoconstriction: the tale of two channels. FASEB J. 9:183-189. 